\title{
Communication \\ Effect of Soil Chemical Properties on the Occurrence and Distribution of Entomopathogenic Fungi in Portuguese Grapevine Fields
}

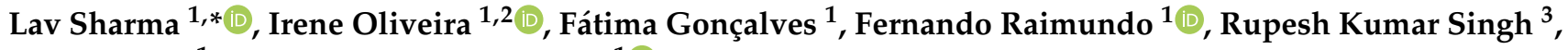 \\ Laura Torres ${ }^{1}$ and Guilhermina Marques ${ }^{1}$ (D) \\ 1 Centre for the Research and Technology of Agro-Environmental and Biological Sciences, University of \\ Trás-os-Montes and Alto Douro (CITAB-UTAD), 5000-801 Vila Real, Portugal; ioliveir@utad.pt (I.O.); \\ mariafg@utad.pt (F.G.); fraimund@utad.pt (F.R.); ltorres@utad.pt (L.T.); gmarques@utad.pt (G.M.) \\ 2 Centre for Computational and Stochastic Mathematics, University of Lisbon (CEMAT-IST-UL), \\ 1049-001 Lisbon, Portugal \\ 3 Centro de Química de Vila Real, Universidade de Trás-os-Montes e Alto Douro, Quinta de Prados, \\ 5000-801 Vila Real, Portugal; rupesh@utad.pt \\ * Correspondence: 1sharma@utad.pt or lavhere@gmail.com
}

Citation: Sharma, L.; Oliveira, I.;

Gonçalves, F.; Raimundo, F.;

Singh, R.K.; Torres, L.; Marques, G. Effect of Soil Chemical Properties on the Occurrence and Distribution of Entomopathogenic Fungi in

Portuguese Grapevine Fields.

Pathogens 2021, 10, 137. https://

doi.org/10.3390/pathogens10020137

Received: 30 November 2020

Accepted: 27 January 2021

Published: 30 January 2021

Publisher's Note: MDPI stays neutra with regard to jurisdictional claims in published maps and institutional affiliations.

Copyright: (c) 2021 by the authors. Licensee MDPI, Basel, Switzerland. This article is an open access article distributed under the terms and conditions of the Creative Commons Attribution (CC BY) license (https:// creativecommons.org/licenses/by/ $4.0 /)$.

\begin{abstract}
Entomopathogenic fungi (EPF) contribute to different ecosystem services. However, factors affecting their natural occurrences in soil remain poorly understood. In a previous study, 81 soil samples were subjected to insect baiting using Galleria mellonella and Tenebrio molitor to isolate EPF from Portuguese vine farms. Here, soils yielding any of the four common EPF, i.e., Beauveria bassiana, Purpureocillium lilacinum, Metarhizium robertsii, and Clonostachys rosea f. rosea, were correlated with their chemical properties. Beauveria bassiana was negatively affected by higher available $\mathrm{P}(p=0.02)$, exchangeable K-ions $(p=0.016)$ and positively affected by higher soil $\mathrm{pH}_{-} \mathrm{H}_{2} \mathrm{O}$ $(p=0.021)$. High exchangeable K-ions inhibited P. lilacinum $(p=0.011)$ and promoted C. rosea f. rosea $(p=0.03)$. Moreover, high available K also suppressed P. lilacinum $(p=0.027)$. Metarhizium robertsii was inhibited by higher organic matter content $(p=0.009)$, higher $\mathrm{C}: \mathrm{N}(p=0.017)$, total $\mathrm{N}(p=0.007)$, and exchangeable Mg-ions ( $p=0.026)$, and promoted by higher exchangeable Na-ions $(p=0.003)$. Nonetheless, mean comparisons and principal component analysis suggested that higher soil $\mathrm{pH}$ and exchangeable Ca-ions have contrasting effects on EPF occurrences, as they promote B. bassiana and inhibit $M$. robertsii. Herbicides did not seem to affect EPF presence. Overall, this study is among the first reports on the effects of soil chemistry on EPF other than Metarhizium, and will facilitate biological pest management approaches.
\end{abstract}

Keywords: Beauveria; biological control; entomopathogenic fungi; Hypocreales; Metarhizium; pest management; soil chemistry; vineyards

\section{Introduction}

Entomopathogenic fungi (EPF) contribute to different ecosystem services. These include nutrient cycling, and regulatory roles, such as pest and plant disease control [1]. EPF can be considered as indicators of soil health [2] and, apart from assisting services for ecosystem functions, they contribute to the sustainable management of agroecosystems $[3,4]$. For example, EPF contribute to plant habitat adaptation against various biotic and abiotic stresses, and provide protection to plants against pathogens and pests [4]. EPF also interact with plants as growth promoters, beneficial rhizosphere colonizers, and biofertilizers [5]. These properties highlight their immense importance for environmentally friendly agriculture. Therefore, the factors that influence their diversity in cultivated soils are of paramount importance and should be thoroughly investigated. 
Plants interact with their surrounding environment by releasing volatile organic compounds (VOCs) produced by leaves, flowers, and roots when exposed to abiotic (drought or mechanical damage) and biotic stress (due to insect herbivores, plant pathogens, or parasitic nematodes). VOCs influence the third trophic level organisms that feed on herbivores, i.e., entomopathogenic nematodes (EPN) and parasitoids/predators, both aboveground and belowground [6-9]. VOCs have been also tested in field conditions [10]. EPF, such as species from Beauveria Vuillemin (Hypocreales: Cordicipitaceae) and Metarhizium Sorokīn (Hypocreales: Clavicipitaceae) also release a range of VOCs [11-15], dictate parasitoidsmediated predation [12], and may repel weevils [14] and mollusks [15].

Both biotic factors (interactions with soil microbes and plants) and abiotic factors (temperature, soil texture, and agricultural inputs) influence the survival of EPF in soil [16]. Earlier research studies in this area have focused primarily on soil physicochemical properties. For example, a previous investigation considered the effects of soil $\mathrm{pH}$, and texture (sand, silt, and clay contents) of Mediterranean soils on the occurrences of EPF [17]. Jabbour and Barbercheck thoroughly investigated effects of soil tillage intensity and cover crop on Metarhizium and other EPF during a three-year transition to organically managed farming in a feed grain rotation. They found an inverse relationship of Metarhizium anisopliae (Metschnikoff) with some soil chemistry traits and trace elements [18]. Clifton et al. measured EPF occurrence and abundance in conventional and organic fields in midwestern USA focusing on presence of Metarhizium and usage of herbicides and fungicides, and found a positive link with organic fertilizer and silt content [19].

Nonetheless, the knowledge of the effects of soil chemical properties on EPF diversity is very limited. Fewer soil chemical constituents were measured and, (a) either the objective was not to check their effect on the natural EPF diversity [20,21], or (b) studies primarily focused only on a few species, e.g., $M$ anisopliae $[18,19,22]$. Those investigations brought a significant advancement in our knowledge on EPF ecology, however; understanding soil properties with respect to the occurrence of other EPF would enhance our knowledge about their survival and/or adaptability in a particular soil type. For example, soils with higher organic matter show higher biological activities, which in turn increase the abundance of EPF antagonists. On the contrary, soils poor in organic matter exhibit a reduced diversity and density of insects, i.e., potential hosts [23]. Studying different soil properties can therefore extend our knowledge about the soil ecology of EPF.

In this direction, only a few recent studies analyzed basic soil chemical constituents, such as total C and N, and correlated them with the occurrence of EPF other than M. anisopliae [23-26]. Few data are available on the natural presence of different EPF with respect to soil cation exchange capacity (a property which assists fungal conidia adsorption onto soils). In this study, we investigated the chemical properties of soils from Portuguese vine farms, by considering multiple variables such as: percentage of organic matter content (OM), total nitrogen $(\mathrm{N})$, total organic carbon $(\mathrm{C})$, available phosphorus $(\mathrm{P})$, available potassium $(\mathrm{K})$, exchangeable ions such as sodium (Na-ions), magnesium (Mg-ions), potassium (K-ions), and calcium (Ca-ions), $\mathrm{pH}$, degree of base saturation (DBS), total acidity (TA), and effective cation exchange capacity $\left(\mathrm{ECEC}\right.$ or $\left.\mathrm{CEC}_{\mathrm{e}}\right)$. Their values were used to assess any impact on the occurrence of four widely known hypocrealean EPF: Beauveria bassiana (Balsamo), Metarhizium robertsii (Bischoff, Rehner and Humber), Purpureocillium lilacinum (Thom) Luangsa-ard, Houbraken, Hywel-Jones and Samson, and Clonostachys rosea f. rosea (Link) Schroers, Samuels, Seifert, and Gams, isolated previously [27]. Furthermore, to enhance variations in the soil chemistry, different soils were considered. The soils were (a) different in texture, i.e., coarse-texture or gross (high proportion of sand) or medium-texture (more balanced mixture of sand, silt, and clay); (b) sampled from varying habitat-types, i.e., cultivated vineyards or adjacent hedgerows which were mainly constituted of pine (Pinus spp. Linnaeus, Pinaceae) and oak (Quercus spp. Linnaeus, Fagaceae) trees; and (c) either treated with herbicides or left untreated. 


\section{Materials and Methods}

\subsection{Farms, Pests, and Sampling Site Description}

The study was conducted in three Douro wine region farms of Portugal with Vitis vinifera L. varieties cultivation: Carvalhas $\left(41^{\circ} 11^{\prime} 12.9^{\prime \prime} \mathrm{N}, 7^{\circ} 32^{\prime} 41.5^{\prime \prime} \mathrm{W}\right)$ (311.9 ha) (mix of red vine varieties: Sousão, Touriga Nacional, Tinto Cão), Granja $\left(41^{\circ} 15^{\prime} 18^{\prime \prime}\right.$ N, $7^{\circ} 28^{\prime} 34^{\prime \prime}$ W) (239 ha) (mix of white wine varieties: Moscatel, Fernão Pires, Verdelho), and S. Luiz (41 ${ }^{\circ} 9^{\prime} 22^{\prime \prime}$ N, $7^{\circ} 36^{\prime} 55^{\prime \prime}$ W) (131.80 ha) (mix of red vine varieties: Touriga Nacional, Touriga Franca, Tinta Roriz, Viosinho, Tinta Barroca) during October and November 2012. The mean annual rainfall and temperature in the farms S. Luiz and Carvalhas ranged between 800 and $1000 \mathrm{~mm}$ and 14 and $16^{\circ} \mathrm{C}$. The farm Granja recorded 1000-1200 mm mean annual rainfall and temperatures ranging between 12 and $14{ }^{\circ} \mathrm{C}$ [28]. Farms are mainly managed through mating disruption for the control of the European grapevine moth Lobesia botrana (Denis and Schiffermüller) (Lepidoptera: Tortricidae). This is a key pest in these Portuguese vineyards and reduces up to $50 \%$ of the total crop yield at the time of harvest by rendering grape clusters susceptible to Botrytis cinerea Pers. (Helotiales: Sclerotiniaceae) resulting in primary and secondary rots [29]. These three farms were selected for their soil chemical properties as they exhibit relatively diverse landscapes (Shannon diversity-index for Carvalhas, S. Luiz, and Granja are 1.57, 1.09, 0.90; Eveness equitability index are 0.75, 0.53, and 0.46, respectively) [29], and the two baiting trap insects were used for soil EPF isolation in these three farms.

The herbicide applications in the farms were performed in March 2012, as follows: $2.5 \mathrm{~L} / \mathrm{ha}$ GOAL ${ }^{\circledR}$ SUPREME (48\% $\mathrm{p} / \mathrm{v}$ oxyfluorfen), and $4 \mathrm{~L} /$ ha ROUNDAP ${ }^{\circledR}$ SUPRA (37.7\% p/p glyphosate) in S. Luiz; 3L/ha MARQUI ${ }^{\circledR}(31 \% \mathrm{p} / \mathrm{p}$ glyphosate), $0.2 \mathrm{~kg} / \mathrm{ha}$ KATANA $^{\circledR}\left(25 \% \mathrm{p} / \mathrm{p}\right.$ flazasulfuron), and 3L/ha TOPZINA ${ }^{\circledR}$ (45.7\% p/p terbuthylazine) in Carvalhas; and 3L/ha FUEGO ${ }^{\circledR}\left(22.3 \% \mathrm{p} / \mathrm{v}\right.$ oxyfluorfen), and 3L/ha ROUNDAP ${ }^{\circledR}$ SUPRA (37.7\% p/p glyphosate) in Granja. No fertilizers were added in these farms for the mentioned year. More details about the usage of herbicide, the rapid texture of soil, and the chemical properties with respect to the sampling sites are provided in the Supplementary Table S1.

\subsection{Soil Sampling}

Soils were sampled from the above farms by digging up the top $20 \mathrm{~cm}$ of the soil surface using a soil core borer (width $=20 \mathrm{~mm}$ ). Approx. $2 \mathrm{~kg}$ of soil was collected in total from each sampling site. For each sample, five subsamples were collected within an area of $0.25 \mathrm{~m}^{2}$ and mixed to obtain one sample per sampling site. Sampling sites were chosen at a distance of $20 \mathrm{~m}$ away. Additional details on the sampling scheme are provided in an earlier study [27]. Sampling tools were washed with 5\% sodium hypochlorite $(\mathrm{NaOCl})$ to avoid any possible fungal contamination between sites and all samples were treated independently. Approx. $1 \mathrm{~kg}$ of soil per sample was sent to the soil laboratory within the campus for soil analysis. Samples were air-dried and sieved with a $2 \mathrm{~mm}$ screen, and preserved for chemical analyses using conventional techniques. Remaining $1 \mathrm{~kg}$ portions of soil were processed immediately, i.e., within $24 \mathrm{~h}$ of the sampling, as described below.

\subsection{Insect Rearing and Baiting}

As a fungus can have different ecological roles, the possibility of a wrong functional annotation cannot be neglected [30]. A selective medium or a DNA-based approach is not sufficient to determine if a fungus is an entomopathogen or can just be a saprotroph or a phytopathogen. For example, a Clonostachys spp., Clonostachys rhizophaga, is a phytopathogen [31], whereas C. rosea f. rosea is an EPF [27]. Hence, insect baiting was preferred over soil suspension culture on selective media or a DNA based approach, as described $[27,28]$. Moreover, insect baiting is a widely accepted technique for the isolation of EPF from soil and many studies have demonstrated that it is better than soil suspension cultures on selective media $[32,33]$. However, using just one baiting trap insect can 
underestimate the presence of a particular EPF. For example, when the effectiveness of the baiting trap insects Galleria mellonella Linnaeus (Lepidoptera: Pyralidae) and Tenebrio molitor Linnaeus (Coleoptera: Tenebrionidae) for EPF isolation was compared, it was noticed that the former was more prone to infections by B. bassiana, and the latter to M. robertsii [27]. Therefore, the combination of both baiting trap insects was used in this study. Out of the 81 soil samples, 35 could yield at least one of the concerned EPF (B. bassiana, M. robertsii, P. lilacinum, and/or C. rosea f. rosea) that were studied for the soil chemical properties. Seven random soil samples that did not yield any EPF isolate were also analyzed, as negative controls. A total of 42 soil samples were examined, i.e., 21 from S. Luiz, 11 from Carvalhas, and 10 from Granja (see details in Supplementary Table S1). The insect larvae and their foods were bought from La Grilleria, Spain (www.lagrilleria.es) and were reared at $25 \pm 2{ }^{\circ} \mathrm{C}, 50-60 \% \mathrm{RH}, 16 \mathrm{~h} \mathrm{~L}: 8 \mathrm{~h} \mathrm{D}$ photoperiod.

For insect baiting, the soils were spread and left open overnight to equilibrate moisture content, adding the insect larvae the next morning for EPF isolation. The larvae of G. mellonella were given a heat shock in a water bath at $56^{\circ} \mathrm{C}$ prior to baiting to reduce their tendency to form silk webs, which could hinder the fungal exposure during soil baiting, as suggested by Meyling and Eilenberg [34]. A total of $1 \mathrm{~kg}$ of soil was baited with 8 healthy late (fifth) instar larvae of each of the two baiting trap insects-G. mellonella and T. molitor. Therefore, $1 \mathrm{~kg}$ soil was divided into four $250 \mathrm{~g}$ bowls, each baited with 4 larvae of a same insect, accounting for $8+8$, i.e., 16 larvae used in total per soil sampling site. Bowls were kept in an environmental camber (Panasonic MLR-352H-PE) at $22{ }^{\circ} \mathrm{C}$ and $85 \%$ relative humidity in dark. They were gently shaken periodically and kept upside down to ensure that the larvae reached most soil parts in the bowl [34,35]. The larvae were baited for three weeks as previously suggested [35], and were checked every second day for fungal growth. Larvae undergoing pupation, if any, were also tested for infection. The schedules were strictly monitored to ensure that larvae with foul smell or with nematodes emergence were constantly discarded.

\subsection{Fungal Isolation and Screening}

Insect cadavers were washed with $1 \% \mathrm{NaOCl}$ for $3 \mathrm{~min}$, followed by 3 distinct washes with sterilized water for 1 minute each. Oatmeal agar supplemented with $0.6 \mathrm{~g} / \mathrm{L}$ cetyl trimethyl ammonium bromide (CTAB) (Sigma) and $0.5 \mathrm{~g} / \mathrm{L}$ chloramphenicol (Acros) [36], and potato dextrose agar (PDA) supplemented with $0.05 \mathrm{~g} / \mathrm{L}$ tetracycline (Acros) and $0.1 \mathrm{~g} / \mathrm{L}$ streptomycin (Acros) were used for fungal isolation. Furthermore, for repeated culturing Oatmeal agar, PDA, and Sabouraud dextrose agar (SDA) (Prolabo) were used to obtain single colony cultures. To ensure the infectivity of the isolates, Koch's postulates were verified as described in earlier studies [36-38]. In brief, sporulating fungi were excised from culture media and mixed in $0.02 \%$ Tween 20 solution (in sterilized distilled water). Fungal conidia concentration was adjusted to a $10^{8}$ conidia $/ \mathrm{mL}$ and then 5 larvae of each insect were dipped into the solution for $3 \mathrm{~s}$. The larvae were then incubated for a week at $22{ }^{\circ} \mathrm{C}$ in a petri dish at $85 \% \mathrm{RH}$, inside an environmental chamber, in the dark, and checked for mortality [27]. The tests for contamination were performed in parallel, as described and no evidence of external or cross-contamination was found [39]. Only those fungi that could kill the larvae within the first week were further considered as EPF.

\subsection{Fungal Identification}

The pure cultures of the EPF were then identified morphologically and through molecular methods. In brief, fungal morphology was first observed using a low magnifying stereomicroscope (Olympus SZX9, 40X), followed by their microscopic identification using a light microscope (Olympus BX51, 400X). For molecular identification, fungal DNA was extracted as mentioned by Möller et al. [40] and hard to crush mycelium was broken using beads, as described [41]. The nuclear internal transcribed spacer region of the fungal ribosomal DNA (nrITS) was amplified with PCR, sequenced, and aligned with existing type strain sequences available in Genbank using BLASTn, as described [27,42]. 


\subsection{Soil Chemical Analyses}

Different soil chemical properties were analyzed. In brief, soil $\mathrm{pH}$ was measured after preparing a soil-water suspension. Total organic carbon analyzer (Primacs SNC100, Skalar Analytical, Breda, The Netherlands) was used to determine OM. Total N was estimated through Kjeldahl method and molecular absorption spectrophotometry was used for its quantification [43]. Extraction of $\mathrm{P}$ and $\mathrm{K}$ was performed using the Egnér-Riehm method, and for determination a spectrophotometer and a flame emission photometer (iCE ${ }^{\mathrm{TM}} 3300$ AAS, Thermo Scientific ${ }^{\mathrm{TM}}$, Breda, North Brabant, The Netherlands) were used, respectively. Atomic absorption spectrophotometry and subsequent ammonium acetate extraction at $\mathrm{pH} 7.0$ were used to measure the amounts of exchangeable cations and bases [44]. Exchangeable acidity was measured using the titration method [45]. $\mathrm{CEC}_{\mathrm{e}}$ was measured by summing exchangeable acidity and exchangeable bases, and the degree of base saturation was estimated by adding up the exchangeable bases, dividing it by $\mathrm{CEC}_{\mathrm{e}}$, and then multiplying by 100 .

\subsection{Data Analyses}

Normalities of the distributions analyzed and soil samples were grouped for the absence or presence of each EPF, independently. Student's $t$-tests were used to determine differences between means of the soil variables for the presence/absence of each EPF. ANOVA was used to compare means between grouped factors. When normality was not assumed, nonparametric tests such as Kruskal-Wallis and Mann-Whitney were used instead, and subsequent unilateral significance $(p<5 \%)$ was obtained. In each nonparametric test for independent samples, the level of significance was based on the exact distribution of a statistical test, since the sample is small, sparse, and is poorly balanced. The Mann-Whitney $U$ test with unequal sample sizes was not performed as the unequal group sizes may limit the statistical power. Instead, a Mann-Whitney $U$ test with a Monte Carlo simulation (10,000 samples and a 0.95 confidence interval) was performed to evaluate the consistency of significant values from exact tests. Monte Carlo simulations were also used to gain better and more valid estimations of the obtained measures. Dimensionality reduction was performed on transformed data using Principal Component Analysis (PCA) and non-metric multidimensional scaling (NMDS). Software IBM SPSS Statistics version 22 (IBM, North Castle, Westchester, NY, USA) and XLSTAT version 2018.2 (Addinsoft, Bordeaux, Nouvelle-Aquitaine, France) were used to perform statistical data processing, and 3D scatter plots were made using NCSS version 12 (NCSS, Kaysville, Davis, UTAH, USA). Effect size analysis was performed using the software $G^{*}$ power ver. 3.1(University of Düsseldorf, Düsseldorf, Germany) [46].

\section{Results}

The OM and chemical properties of 42 soil samples were studied in terms of EPF occurrence. The corresponding statistics, $T$-values $(t)$ or Mann-Whitney $U$-values $(U)$ and $p$-values, are shown in Table 1. Details of the soil properties are provided in the Supplementary Table S1. All the significant values also resulted as significant by the Monte Carlo simulation.

\subsection{Effects of Soils Chemical Properties, OM, and Herbicide Usage on EPF}

Beauveria bassiana was associated with soils with less total acidity $(p=0.043)$ or higher pH_ $\mathrm{H}_{2} \mathrm{O}(p=0.021)$ (Figure 1, Table 1). Although some trends were noticed, in general, DBS and $\mathrm{CEC}_{\mathrm{e}}$ did not affect EPF occurrences (Figure 1, Table 1). Among exchangeable ions, higher K-ions had a significant negative effect on the occurrence of B. bassiana $(p=0.016)$ and P. lilacinum ( $p=0.011)$, and a significant positive effect on the occurrence of $C$. rosea $\mathrm{f}$. rosea $(p=0.03)$. Excess of other exchangeable ions, i.e., $\mathrm{Mg}$-ions and Na-ions, had inhibiting ( $p=0.026)$ and promoting $(p=0.003$ ) effects on M. robertsii, respectively. Purpureocillium lilacinum was also recovered from soils with higher Mg-ions, however, non-significantly $(p=0.077)$ (Figure 1, Table 1). 
Metarhizium robertsii was inhibited by higher $\mathrm{N}(p=0.007)$ and similarly, by higher C:N $(p=0.017)$. EPF in general were reported in soils with less $\mathrm{N}, \mathrm{P}$, and $\mathrm{K}$, although there were a few marginal exceptions (Figure 1). Higher P inhibited B. bassiana $(p=0.02)$, and higher $\mathrm{K}$ reduced P. lilacinum ( $p=0.027)$. Higher $P$ had a minor inhibitory effect on $M$. robertsii, i.e., $(p=0.121)$ (Figure 1). Metarhizium robertsii was inhibited by OM $(p=0.009)$ whereas the other EPF did not seem to be affected by OM (Figure 1, Table 1). The mean values of all the soil variables with respect to the presence and absence of an EPF are shown in Table 1. Effect sizes for the significant observations are presented in Table S2. It was also noticed that the herbicide usage did not affect the presence of EPF as EPF could be isolated exactly equally from herbicide treated $(N=20 / 24)$ as well as untreated $(N=15 / 18)$ soils, i.e., $83.34 \%$ in each case (Table S1).

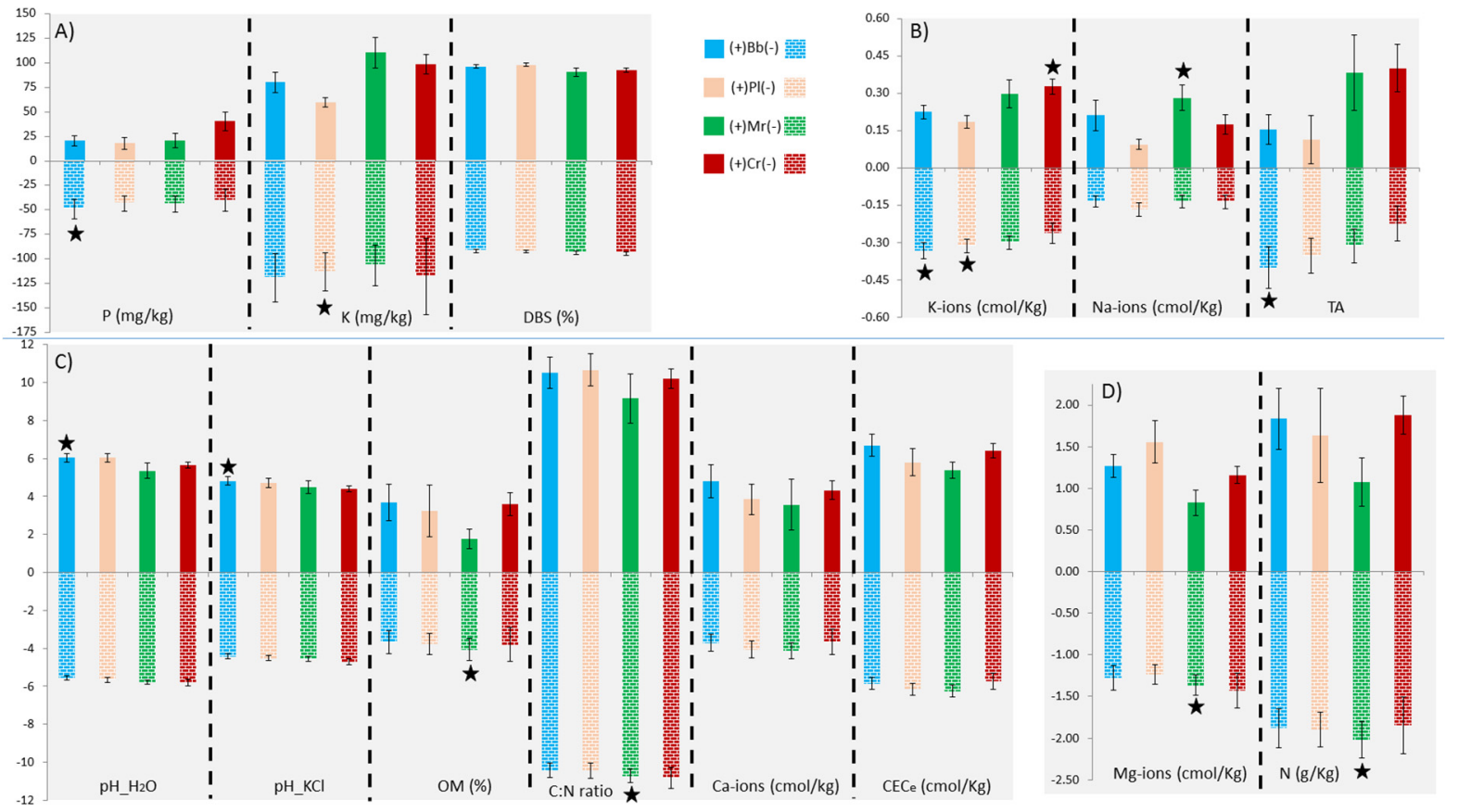

Figure 1. Effects of the soil properties on the occurrences on entomopathogenic fungi. Abbreviations B.b, P.l, M.r, and C.r stand for the entomopathogenic fungi Beauveria bassiana, Purpureocillium lilacinum, Metarhizium robertsii, and Clonostachys rosea f. rosea, respectively. Presence (+) and absence (-) are shown on the positive and negative Y axis, respectively. Unilateral significant observations, i.e., $p<5 \%$ is marked with an asterisk. Due to the difference in the scales used to access soil properties, soil variables are grouped according to the scales appropriate for their visualization as well as resolution. Overall, four different scales were used for the variables in the group (A-D). The units used for these scales, for e.g., $\mathrm{cmol} / \mathrm{kg}, \mathrm{g} / \mathrm{kg}$, $\mathrm{mg} / \mathrm{kg}$, and \%, are mentioned alongside the measured soil variable. DBS, TA, OM, and CEC $\mathrm{e}$ are: mean degree of base saturation, total acidity, organic matter, and effective cation exchange capacity, respectively. 
Table 1. Statistical test, mean value for fungal absence and presence, and significance values for the effects of the different soil properties on the occurrences of entomopathogenic fungi.

\begin{tabular}{|c|c|c|c|c|c|c|c|c|c|c|c|c|c|c|c|c|}
\hline \multirow{2}{*}{$\begin{array}{c}\text { Soil } \\
\text { Properties }\end{array}$} & \multirow[b]{2}{*}{$\mathrm{MW}-\mathrm{U}^{\mathrm{a}}$} & \multicolumn{2}{|c|}{ Beauveria bassiana } & \multirow[b]{2}{*}{$p^{\mathrm{a}}$} & \multirow[b]{2}{*}{$M W-U^{a}$} & \multicolumn{2}{|c|}{ Purpureocillium lilacinum } & \multirow[b]{2}{*}{$p^{\mathrm{a}}$} & \multirow[b]{2}{*}{$M W-\mathrm{U}^{\mathrm{a}}$} & \multicolumn{2}{|c|}{ Metarhizium robertsii } & \multirow[b]{2}{*}{$p^{\mathrm{a}}$} & \multirow[b]{2}{*}{$M W-\mathrm{U}^{\mathrm{a}}$} & \multicolumn{2}{|c|}{ Clonostachys rosea f. rosea } & \multirow[b]{2}{*}{$p^{\mathrm{a}}$} \\
\hline & & $\begin{array}{l}\text { Mean for } \\
\text { Absence }\end{array}$ & $\begin{array}{l}\text { Mean for } \\
\text { Presence }\end{array}$ & & & $\begin{array}{l}\text { Mean for } \\
\text { Absence }\end{array}$ & $\begin{array}{l}\text { Mean for } \\
\text { Presence }\end{array}$ & & & $\begin{array}{l}\text { Mean for } \\
\text { Absence }\end{array}$ & $\begin{array}{l}\text { Mean for } \\
\text { Presencee }\end{array}$ & & & $\begin{array}{l}\text { Mean for } \\
\text { Absence }\end{array}$ & $\begin{array}{l}\text { Mean for } \\
\text { Presence }\end{array}$ & \\
\hline $\mathrm{P}(\mathrm{mg} / \mathrm{kg})$ & 113 & $49.37 \pm 52.57$ & $20.38 \pm 17.79$ & 0.02 & 60 & $43.43 \pm 48.61$ & $17.95 \pm 14.10$ & 0.11 & 87 & $44.28 \pm 49.48$ & $20.99 \pm 19.55$ & 0.121 & 208 & $40.13 \pm 47.55$ & $40.6 \pm 46.75$ & 0.419 \\
\hline $\mathrm{K}(\mathrm{mg} / \mathrm{kg})$ & 140.5 & $119.59 \pm 133.11$ & $80.48 \pm 37.29$ & 0.097 & 43 & $113.90 \pm 119.40$ & $60 \pm 11.22$ & 0.027 & 78.5 & $106.81 \pm 123.19$ & $110.86 \pm 0.77$ & 0.07 & 182 & $118.98 \pm 165.95$ & $99.01 \pm 48.01$ & 0.193 \\
\hline $\begin{array}{c}\text { OM content } \\
(\%)\end{array}$ & 168 & $3.69 \pm 3.28$ & $3.7 \pm 3.47$ & 0.295 & 85 & $3.75 \pm 3.37$ & $3.24 \pm 3.01$ & 0.396 & 54.5 & $4.08 \pm 3.45$ & $1.77 \pm 1.34$ & 0.009 & 207 & $3.81 \pm 3.79$ & $3.6 \pm 2.96$ & 0.409 \\
\hline $\mathrm{N}(\mathrm{g} / \mathrm{kg})$ & 169 & $1.88 \pm 1.26$ & $1.83 \pm 1.32$ & 0.305 & 82 & $1.89 \pm 1.28$ & $1.64 \pm 1.26$ & 0.353 & 51.5 & $2.02 \pm 1.29$ & $1.08 \pm 0.77$ & 0.007 & 200.5 & $1.85 \pm 1.44$ & $1.88 \pm 1.14$ & 0.347 \\
\hline $\mathrm{C}: \mathrm{N}$ & 168 & $0.0104 \pm 0.0017$ & $0.01 \pm 0.002$ & 0.999 & 78 & $0.01 \pm 0.001$ & $0.01 \pm 0.0016$ & 0.298 & 60 & $0.01 \pm 0.0018$ & $0.01 \pm 0.0011$ & 0.017 & 165 & $0.01 \pm 0.001$ & $0.01 \pm 0.001$ & 0.097 \\
\hline $\mathrm{p} \mathrm{H} \__{2} \mathrm{H}_{2} \mathrm{O}$ & 114.5 & $5.55 \pm 0.67$ & $6.04 \pm 0.83$ & 0.021 & $\begin{aligned} t^{\mathrm{b}} & =-1.06 \\
\mathrm{df} \mathrm{b}^{\mathrm{b}} & =40\end{aligned}$ & $5.66 \pm 0.77$ & $6.03 \pm 0.5$ & $0.147^{\mathrm{b}}$ & $\begin{array}{c}t^{\mathrm{b}}=1.336 \\
\mathrm{df} \mathrm{f}^{\mathrm{b}}=40\end{array}$ & $5.77 \pm 0.68$ & $5.36 \pm 1.03$ & $0.094 \mathrm{~b}$ & $\begin{array}{c}t^{\mathrm{b}}=0.596 \\
\mathrm{df} \mathrm{f}^{\mathrm{b}}=40\end{array}$ & $5.78 \pm 0.76$ & $5.64 \pm 0.75$ & $0.277^{\mathrm{b}}$ \\
\hline pH_KCl & $\begin{array}{c}t^{b}=-1.688 \\
\mathrm{df} \mathrm{b}=40\end{array}$ & $4.41 \pm 0.71$ & $4.82 \pm 0.77$ & $0.049 \mathrm{~b}$ & $\begin{aligned} t^{\mathrm{b}} & =-0.57 \\
\mathrm{df} \mathrm{b}^{\mathrm{b}} & =40\end{aligned}$ & $4.52 \pm 0.77$ & $4.72 \pm 0.54$ & $0.286^{\mathrm{b}}$ & 110 & $4.55 \pm 0.72$ & $4.49 \pm 0.91$ & 0.346 & $\begin{array}{c}t^{\mathrm{b}}=1.294 \\
\mathrm{df} \mathrm{f}^{\mathrm{b}}=40\end{array}$ & $4.71 \pm 0.68$ & $4.41 \pm 0.78$ & $0.101 \mathrm{~b}$ \\
\hline TA & 125 & $0.40 \pm 0.45$ & $0.15 \pm 0.22$ & 0.043 & 65.5 & $0.35 \pm 0.42$ & $0.12 \pm 022$ & 0.152 & 109 & $0.31 \pm 0.41$ & $0.38 \pm 0.4$ & 0.334 & 175 & $0.22 \pm 0.29$ & $0.4 \pm 0.46$ & 0.137 \\
\hline DBS $(\%)$ & 133 & $91.90 \pm 9.52$ & $96.41 \pm 5.76$ & 0.068 & 65.5 & $92.67 \pm 9.03$ & $97.92 \pm 3.96$ & 0.152 & 103 & $93.87 \pm 8.38$ & $90.42 \pm 10.47$ & 0.265 & 192 & $94.49 \pm 7.53$ & $92.41 \pm 9.57$ & 0.261 \\
\hline $\begin{array}{c}\mathrm{Ca}^{2+} \\
(\mathrm{cmol} / \mathrm{kg})\end{array}$ & 154.5 & $3.7 \pm 2.06$ & $4.81 \pm 2.95$ & 0.18 & 91 & $4.07 \pm 2.47$ & $3.85 \pm 1.89$ & 0.485 & 83 & $4.14 \pm 2.18$ & $3.57 \pm 3.47$ & 0.096 & 160 & $3.66 \pm 2.33$ & $4.33 \pm 2.45$ & 0.077 \\
\hline $\begin{array}{c}\mathrm{Mg}^{2+} \\
(\mathrm{cmol} / \mathrm{kg})\end{array}$ & 162.5 & $1.28 \pm 0.790$ & $1.27 \pm 0.49$ & 0.242 & 55 & $1.24 \pm 0.71$ & $1.56 \pm 0.57$ & 0.077 & 65 & $1.36 \pm 0.72$ & $0.83 \pm 0.40$ & 0.026 & 201.5 & $1.43 \pm 0.9$ & $1.16 \pm 0.5$ & 0.356 \\
\hline $\begin{array}{c}\mathrm{K}^{+} \\
(\mathrm{cmol} / \mathrm{kg})\end{array}$ & 110 & $0.33 \pm 0.18$ & $0.22 \pm 0.10$ & 0.016 & 35.5 & $0.31 \pm 0.17$ & $0.19 \pm 0.06$ & 0.011 & 115 & $0.30 \pm 0.17$ & $0.3 \pm 0.14$ & 0.408 & 142 & $0.26 \pm 0.17$ & $0.33 \pm 0.15$ & 0.03 \\
\hline $\begin{array}{c}\mathrm{Na}^{+} \\
(\mathrm{cmol} / \mathrm{kg})\end{array}$ & 154 & $0.14 \pm 0.12$ & $0.21 \pm 0.23$ & 0.18 & 76 & $0.17 \pm 0.17$ & $0.09 \pm 0.05$ & 0.273 & 45 & $0.13 \pm 0.15$ & $0.28 \pm 0.14$ & 0.003 & 208 & $0.14 \pm 0.11$ & $0.18 \pm 0.19$ & 0.419 \\
\hline $\begin{array}{c}\mathrm{CEC} \\
(\mathrm{cmol} / \mathrm{kg})\end{array}$ & 168 & $5.84 \pm 2.41$ & $6.69 \pm 0.86$ & 0.295 & 90 & $6.15 \pm 2.75$ & $5.80 \pm 1.79$ & 0.47 & 82 & $6.25 \pm 2.48$ & $5.36 \pm 3.49$ & 0.09 & 160 & $5.71 \pm 2.91$ & $6.4 \pm 2.44$ & 0.077 \\
\hline
\end{tabular}

Abbreviations stand for: available phosphorous (P), available potassium $(\mathrm{K})$, organic matter $(\mathrm{OM})$, total nitrogen $(\mathrm{N})$, carbon-nitrogen ration $(\mathrm{C}: \mathrm{N})$, total acidity $(\mathrm{TA})$, degree of base saturation (DBS), exchangeable calcium ions $\left(\mathrm{Ca}^{2+}\right)$, exchangeable magnesium ions $\left(\mathrm{Mg}^{2+}\right)$, exchangeable potassium ions $\left(\mathrm{K}^{+}\right)$, exchangeable sodium ions $\left(\mathrm{Na}^{+}\right)$, and effective cation exchange capacity $\left(\mathrm{CEC}_{\mathrm{e}}\right)$. a Values are obtained by nonparametric statistical method, i.e., Mann-Whitney Test $U$-value (MW-U), unless stated otherwise. ${ }^{\mathrm{b}}$ Values are obtained by parametric statistical method, i.e., Student's $t$-test, $T$-value $(t)$, and degrees of freedom (df) are mentioned. Significant observations $(p<5 \%)$ are marked as bold. 


\subsection{Biological Proximities and Related Factors}

Principal Component Analysis (PCA) was performed to understand the role of different soil properties on the occurrences of EPF and their subsequent clustering. As the significant effects of soil variables were only observed for $M$. robertsii and B. bassiana, the PCA was performed for three groups of EPF: B. bassiana, M. robertsii, and others (P. lilacinum and C. rosea f. rosea). First three components, i.e., PC1, PC2, and PC3 accounted for the $73.81 \%$ of the total variance, i.e., $38.10 \%, 20.62 \%$, and $15.09 \%$, respectively (Figure 2, Table S3). Principal component 1 could distinguish between the soils with and without $M$. robertsii (Figure 2A,B). It was noticed that $M$. robertsii isolations were negatively correlated with the higher amounts of $\mathrm{OM}$, higher $\mathrm{C}: \mathrm{N}, \mathrm{N}, \mathrm{pH} \_\mathrm{H}_{2} \mathrm{O}, \mathrm{Mg}$-ions, Ca-ions, and $\mathrm{CEC}_{\mathrm{e}}$. As $\mathrm{pH}$ was negatively correlated with $M$. robertsii, it was shown that the soils higher in TA tended to favor $M$. robertsii isolations (Figure 2A,B). Principal component 2 clustered B. bassiana isolations with some exceptions (Figure 2A,C). It was found that B. bassiana was less prevalent in soils with higher K, P, TA, and K-ions. Soils with higher pH_ $\mathrm{H}_{2} \mathrm{O}$ and Ca-ions instead tended to have higher occurrence of $B$. bassiana (Figure 2). Relationships among different soil variables are shown in Figure 2E. Factor loading and eigenvectors for different soil chemical characteristics are presented in the Supplementary Table S3.
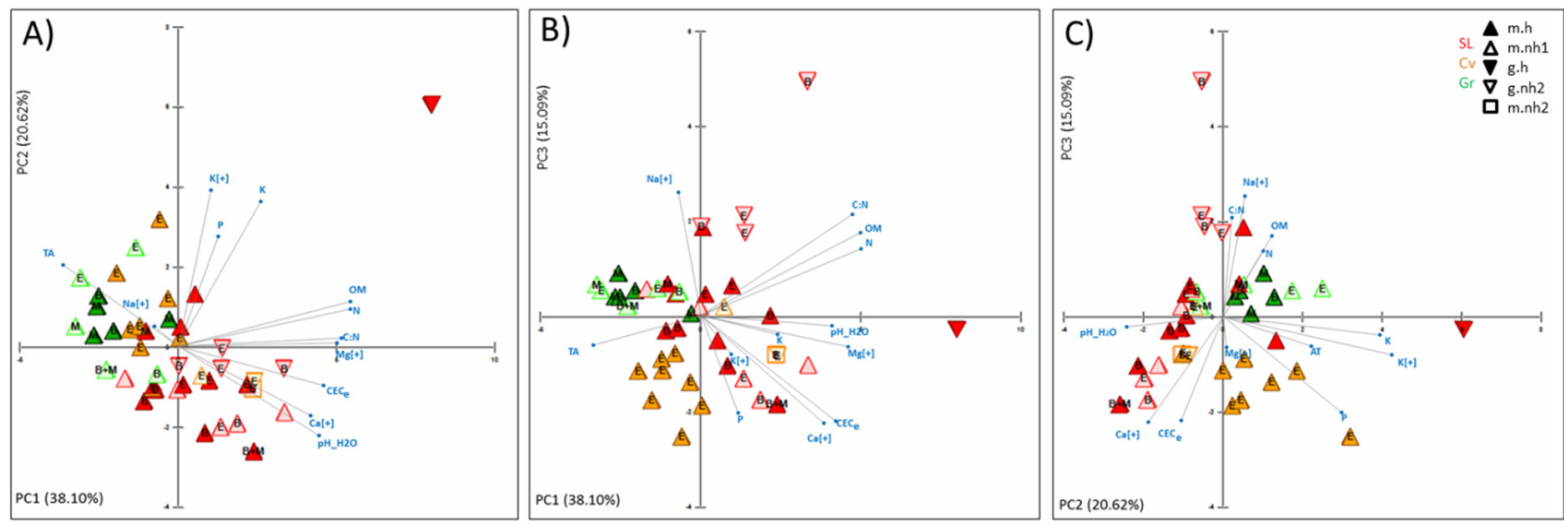

D)

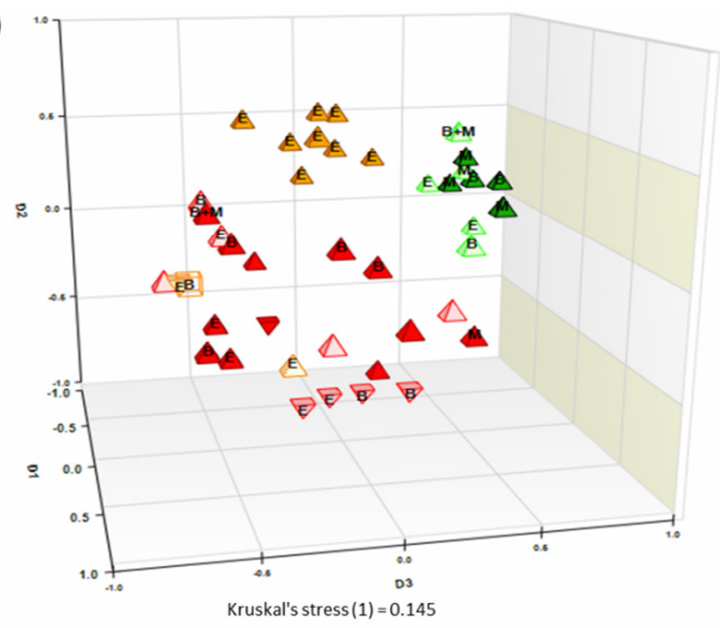

E)

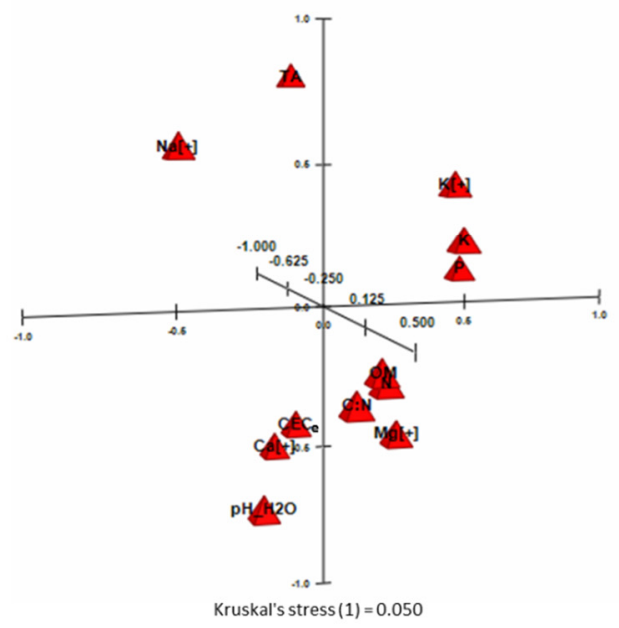

Figure 2. Clustering of soil samples harboring entomopathogenic fungi based on soil properties using principal component analysis (PCA) and non-metric multidimensional scaling (NMDS). (A) PC1 vs. PC2. (B) PC1 vs. PC3. (C) PC2 vs. PC3. (D) 3D-NMDS of soil samples. (E) 3D-NMDS of soil properties. Exchangeable cations are mentioned with a plus [+] sign. Farm types include S. Luiz (SL), Carvalhas (Cv), and Granja (Gr). Rapid texture is classified as gross (g) and medium (m). Entomopathogenic fungi are marked as E, if otherwise stated, i.e., B. bassiana (B), and M. robertsii (M). Other representations are soils with herbicide treatment (h), soils without any herbicide application and collected from vineyards (nh1), and soils from adjacent natural hedgerows which, by default, were never treated with herbicides (nh2). 


\section{Discussion}

Soil characteristics can affect fungal communities and host-microbe interactions [20]. Studying soils where EPF spend a considerable part of their life cycle is of a high relevance for the management of their populations. In this study, soil physicochemical properties were analyzed for common soil EPF. Beauveria bassiana showed significant affinity to soils with less acidity or higher $\mathrm{pH}$, a situation consistent with another study that also reported the association of $B$. bassiana with soils with higher $\mathrm{pH}[17,25]$. In the present study, $\mathrm{pH}$, TA, DBS, and $\mathrm{CEC}_{\mathrm{e}}$ did not show a significant effect on other EPF. Previous investigations also reported no significant effects on important factors such as soil $\mathrm{pH}$ and $\mathrm{CEC}_{\mathrm{e}}$ on Metarhizium occurrence [18,47].

Higher $\mathrm{N}$ tended to inhibit the occurrences of EPF, with the exception of C. rosea f. rosea, as higher $\mathrm{N}$ might have favored the growth of other fungi which could be competitors or consumers of EPF, or decomposers [48,49]. Our data showed that N, P, and K availability tended to reduce EPF occurrence, with some marginal exceptions (Figure 1). A negative correlation between Metarhizium and N content was noticed earlier [19]. It was also observed that fertilizers influence above- and belowground components which ultimately may reduce efficacy of biological control by EPF [50]. Koorem et al. reported that the abundance of soil arbuscular mycorrhizal fungi was negatively correlated with soil P [51]. Moreover, addition of NPK fertilizers was also reported to reduce the density of other entomopathogens such as nematodes [52]. Jaronski suggested that soils receiving high fertilizer input are dominated by bacteria [16]. Clifton et al. argued that soil microorganisms, particularly bacteria, exploit elevated nitrogen concentration and hence, outcompete EPF propagules for substrates [19]. In other studies, it was noticed that nutrient stressed environment, for e.g., soils with lesser N, may enhance EPF virulence and germination, as in the case of Metarhizium [24,53]. Moreover, EPF can mobilize insect-derived $\mathrm{N}$ in the scarcity of plant-derived $\mathrm{N}$, and trade it for plant carbohydrates as endophytes [24,54]. Such property imparts an advantage for EPF over other soil microorganisms as lower soil nutrient levels reduce competition and antagonist presence [24].

Herbicides i.e., glyphosate, oxyfluorfen, flazasulfuron, and terbuthylazine applications, did not affect the field EPF occurrence. Various studies have reported negative effects of glyphosate [55] and oxyfluorfen [56] can significantly impact EPF vegetative growth and sporulation in-vitro. However, Clifton et al. also did not notice any significant impact of glyphosate and glufosinate-ammonium on EPF in field assays and also argued that herbicides do not affect the natural insect infection rates of EPF, such as Metarhizium [19].

Organic matter content had no effect on EPF occurrences apart from Metarhizium (Figure 1). An increase in OM subsequently increases $\mathrm{CEC}_{\mathrm{e}}$, which enhances fungal conidia adsorption [17]. However, another study reported a negative association of $\mathrm{OM}$ with Metarhizium, comparative to ours [18]. Previous studies suggested that OM increases the biological activity in soils enhancing the growth of other saprotrophic fungi and eventually reducing the resources for EPF. Beauveria and Metarhizium are poor competitors for OM compared to saprotrophic fungi that are ubiquitous in soils [35,57]. Klingen et al. suggested that although a high OM may increase the EPF adsorption, these fungi maybe subsequently killed by saprotrophic fungi, in such soils [58]. Hence, it was not surprising that a higher $\mathrm{C} / \mathrm{N}$, resulting from a high $\mathrm{OM}$, significantly increased soil fusaria in Portuguese vineyards [28]. Bidochka et al. also noticed that Metarhizium prefers agricultural and cultivated habitats that tend to have lower OM when compared with forest or semi-natural habitats [59]. We observed that $M$. robertsii could only be isolated from tilled vineyard soils and not from untilled hedgerows dominated by oaks and pine trees.

As the majority of soils had a medium texture (a balanced mix of sand, silt, and clay) rather than a gross texture (a high proportion of sand), we could not find a conclusive correlation for this parameter, although, it was noticed that M. robertsii was only isolated from medium-textured soils (Table S1). Garrido-Jurado et al. noticed that the availability of Metarhizium conidia was lower in sandy soils [20], and adequate sand content eventually promotes the conidia mobility and may promote percent infection [20,25]. Medium textured 
soils, with a balanced sand and clay content, can benefit EPF, as their adsorption onto clay particles can lead to a better nutrient availability for the fungus, due to enhanced iron solubility [20]. Clay, in fact, is used in many biological control formulations, particularly as coatings of clay/chitosan complex [60].

\section{Conclusions}

Two different approaches - comparisons of means and factor analyses-were adopted to study the variations in the chemistry of soils harboring different EPF. It was found that both approaches complement each other. Principal component analysis based on the soil chemical properties showed two factors which separated M. robertsii from B. bassiana. Properties such as higher soil $\mathrm{pH}$ and $\mathrm{Ca}$-ions have contrasting effects as they both promote B. bassiana and inhibit $M$. robertsii. Moreover, different profiles were observed for each EPF. It was noticed that while soil OM, N, higher C:N, Mg-ions, and $\mathrm{CEC}_{\mathrm{e}}$ inhibit $M$. robertsii the most, inhibition of $B$. bassiana mainly occurs in soils with higher acidity, $\mathrm{K}$, $\mathrm{P}$, and K-ions. Therefore, these chemical indicators can be used to predict the soil quality in terms of EPF, and subsequent soil amendments to be undertaken. However, a holistic approach is necessary to access the effects of such amendments on other beneficial soil organisms. Garrido-Jurado et al. emphasized the importance of investigating the retention and migration of the infective conidia in soil [20]. Apart from the soil physicochemical properties, electrostatic interactions, and substratum hydrophobicity can play important roles in fungal conidia retention and transport $[20,28]$.

Predicting soil microbial quality based on soil chemical properties could be a promising approach in for sustainable agriculture, to develop methods such as integrated pest management. Both inundative and natural biological control through EPF has been studied in vineyards. Cozzi et al. reported significant mortality of L. botrana in Italian vineyards by B. bassiana, comparable to mortality by Bacillus thuringiensis Cohn (Berlinger) (Bacillales: Bacillaceae) [61]. Sharma et al. [41] investigated natural mycosis of vine mealybug Planococcus ficus (Signoret) (Hemiptera: Pseudococcidae) in vineyards by P. lilacinum. However, the success of biological pest control depends on a number of factors including the effects on non-target arthropods that must be taken into account during field inundative use of EPF. Some EPF, such as Beauveria and Lecanicillium W.Gams \& Zare (Hypocreales: Cordycipitaceae) are also considered as plant disease (powdery mildew, rusts etc.) antagonists, acting through competition for resources, antibiosis, systemic resistance, or even parasitism against soil fungi [62-64]. Hence, such interaction with soil micro-organisms should be examined prior to EPF applications. Interestingly, EPF applications are compatible along with the use of mycoparasites, and in some cases they act in synergy against insect pests [65], probably, because fungal traits imparting entomopathogenicity are also involved in phytopathogen's biocontrol [64]. Nonetheless, the EPF persistence should also be considered, as the ideal condition would be a longer persistence of a specialist EPF against a particular insect-pest, rather than a long-term persistence of a generalist EPF. According to Jaronski, one of the fundamental observations about the interactions of EPF with soil microbes is that non-sterile soils do not allow increase in EPF titers, exhibiting fungistasis [16]. However; recent studies have suggested long term persistence of B. bassiana, M. anisopliae, B. brongniartii in soils for over a year $[27,65]$. Apart from soil microbes, EPF are prone to mycophagy by soil nematodes and oribatid mites, protozoa, collembolans (springtails), enchytraeids, and earthworms. Luckily, evidences of EPF pathogenicity against earthworms and springtails are rare, if not absent [65]. To conclude, in plant protection practice, it is important to rely on a holistic approach to understand the relationships of organisms with the habitat, as well as among coexisting species. Further investigations on the ecology of the EPF and soil (micro)-biota would immensely benefit our understanding towards biological control of insect pests, as, for example, functional EPF diversity in vineyards (agricultural soils in this study) can be very different from that of oaks and pine trees (the major constituent of hedgerows in this study) $[27,41]$. Nonetheless, in parallel, such an approach can be extended to other beneficial soil microbes. 
Supplementary Materials: The following are available online at https:/ /www.mdpi.com/2076-081 7/10/2/137/s1, Table S1: Chemical properties and other details of the soils sampled from the farms; Table S2: The effect sizes of significant observations with respect to the entomopathogenic fungi. Table S3: Details of principal component analysis.

Author Contributions: Conceptualization, L.S., F.G., F.R., L.T. and G.M.; Methodology, L.S., I.O., F.G., F.R. and G.M.; Software, L.S., I.O.; Validation, L.S., I.O., F.R. and G.M.; Formal Analysis, L.S., F.G. and I.O.; Investigation, L.S., F.G., L.T. and G.M.; Resources, F.R., L.T. and G.M.; Data Curation, L.S., F.G. and I.O.; Writing-Original Draft Preparation, L.S.; Writing-Review and Editing, I.O., F.G., F.R., L.T., R.K.S. and G.M.; Visualization, L.S. and I.O.; Supervision, L.T. and G.M.; Project Administration, L.T. and G.M.; Funding Acquisition, L.T. and G.M. All authors have read and agreed to the published version of the manuscript.

Funding: Research was funded by the National Funds by FCT-the Portuguese Foundation for Science and Technology under the project UIDB/04033/2020; the EcoVitis project Maximizing Ecosystem Services in "Douro Demarcated Region" Vineyards, funded by FEADER and by National Funds under the Rural Development Programme (PRODER)—PA 24043, 2011-2014—under the fellowship BI/PRODER/Projeto24043/UTAD/2012.

Institutional Review Board Statement: Not applicable.

Informed Consent Statement: Not applicable.

Data Availability Statement: This study evaluates data generated in a previous study (https:/ / doi. org/10.3897/mycokeys.38.26970) with new variables generated in this study. The soil chemistry data obtained in this study with respect to the microbes discussed were not published elsewhere. The Supplementary Data are deposited on the journal website for re-use and validation by research community.

Acknowledgments: The work is a part of L. Sharma's PhD. dissertation at University of Trás-osMontes and Alto Douro, UTAD, Vila Real, Portugal. The authors would like to thank the technicians of the Sogevinus Finewines SA and Real Companhia Velha for their constant cooperation during the investigation.

Conflicts of Interest: The authors declare no conflict of interest.

\section{References}

1. Ghaley, B.B.; Porter, J.R.; Sandhu, H.S. Soil-based ecosystem services: A synthesis of nutrient cycling and carbon sequestration assessment methods. Int. J. Biodivers. Sci. Ecosyst. Serv. Manag. 2014, 10, 177-186. [CrossRef]

2. Barker, C.W.; Barker, G.M. Generalist entomopathogens as biological indicators of deforestation and agricultural land use impacts on waikato soils. N. Z. J. Ecol. 1998, 22, 189-196.

3. Barrios, E. Soil biota, ecosystem services and land productivity. Ecol. Econ. 2007, 64, 269-285. [CrossRef]

4. Lugtenberg, B.J.J.; Caradus, J.R.; Johnson, L.J. Fungal endophytes for sustainable crop production. FEMS Microbiol. Ecol. 2016, 92, fiw194. [CrossRef]

5. Mantzoukas, S.; Eliopoulos, P.A. Endophytic entomopathogenic fungi: A valuable biological control tool against plant pests. Appl. Sci. 2020, 10, 360. [CrossRef]

6. Turlings, T.C.J.; Tumlinson, J.H.; Lewis, W.J. Exploitation of herbivore-induced plant odors by host-seeking parasitic wasps. Science 1990, 250, 1251. [CrossRef]

7. De Moraes, C.M.; Lewis, W.J.; Paré, P.W.; Alborn, H.T.; Tumlinson, J.H. Herbivore-infested plants selectively attract parasitoids. Nature 1998, 393, 570-573. [CrossRef]

8. Rasmann, S.; Köllner, T.G.; Degenhardt, J.; Hiltpold, I.; Toepfer, S.; Kuhlmann, U.; Gershenzon, J.; Turlings, T.C.J. Recruitment of entomopathogenic nematodes by insect-damaged maize roots. Nature 2005, 434, 732-737. [CrossRef]

9. Delory, B.M.; Delaplace, P.; Fauconnier, M.-L.; du Jardin, P. Root-emitted volatile organic compounds: Can they mediate belowground plant-plant interactions? Plant Soil 2016, 402, 1-26. [CrossRef]

10. Heuskin, S.; Béra, F.; Lorge, S.; Leroy, P.; Haubruge, E.; Wathelet, J.-P.; Brostaux, Y.; Lognay, G. A Semiochemical slow-release formulation in a biological control approach to attract hoverflies. J. Environ. Ecol. 2012, 3, 72-85. [CrossRef]

11. Crespo, R.; Pedrini, N.; Juárez, M.P.; Dal Bello, G.M. Volatile organic compounds released by the entomopathogenic fungus Beauveria bassiana. Microbiol. Res. 2008, 163, 148-151. [CrossRef] [PubMed]

12. Cotes, B.; Rännbäck, L.-M.; Björkman, M.; Norli, H.; Meyling, N.; Rämert, B.; Anderson, P. Habitat selection of a parasitoid mediated by volatiles informing on host and intraguild predator densities. Oecologia 2015, 179, 151-162. [CrossRef]

13. Bojke, A.; Tkaczuk, C.; Stepnowski, P.; Gołębiowski, M. Comparison of volatile compounds released by entomopathogenic fungi. Microbiol. Res. 2018, 214, 129-136. [CrossRef] [PubMed] 
14. Lozano-Soria, A.; Picciotti, U.; Lopez-Moya, F.; Lopez-Cepero, J.; Porcelli, F.; Lopez-Llorca, L.V. Volatile organic compounds from entomopathogenic and nematophagous fungi, repel banana black weevil (Cosmopolites sordidus). Insects 2020, 11, 509. [CrossRef] [PubMed]

15. Khoja, S.; Eltayef, K.M.; Baxter, I.; Myrta, A.; Bull, J.C.; Butt, T. Volatiles of the entomopathogenic fungus, Metarhizium brunneum, attract and kill plant parasitic nematodes. Biol. Control 2021, 152, 104472. [CrossRef]

16. Jaronski, S.T. Soil ecology of the entomopathogenic ascomycetes: A critical examination of what we (think) we know. In Use of Entomopathogenic Fungi in Biological Pest Management; Maniana, K., Ekesi, S., Eds.; Research SignPosts: Trivandrum, India, 2007; pp. 91-144.

17. Quesada-Moraga, E.; Navas-Cortés, J.A.; Maranhao, E.A.A.; Ortiz-Urquiza, A.; Santiago-Álvarez, C. Factors affecting the occurrence and distribution of entomopathogenic fungi in natural and cultivated soils. Mycol. Res. 2007, 111, 947-966. [CrossRef]

18. Jabbour, R.; Barbercheck, M.E. Soil management effects on entomopathogenic fungi during the transition to organic agriculture in a feed grain rotation. Biol. Control 2009, 51, 435-443. [CrossRef]

19. Clifton, E.H.; Jaronski, S.T.; Hodgson, E.W.; Gassmann, A.J. Abundance of soil-borne entomopathogenic fungi in organic and conventional fields in the midwestern USA with an emphasis on the effect of herbicides and fungicides on fungal persistence. PLoS ONE 2015, 10, e0133613. [CrossRef]

20. Garrido-Jurado, I.; Torrent, J.; Barrón, V.; Corpas, A.; Quesada-Moraga, E. Soil properties affect the availability, movement, and virulence of entomopathogenic fungi conidia against puparia of Ceratitis capitata (Diptera: Tephritidae). Biol. Control 2011, 58, 277-285. [CrossRef]

21. Asensio, L.; Carbonell, T.; Lopez Jimenez, J.; López Llorca, L. Entomopathogenic fungi in soils from alicante province. Span. J. Agric. Res. 2003, 1, 37-45. [CrossRef]

22. Rath, A.C.; Koen, T.B.; Yip, H.Y. The influence of abiotic factors on the distribution and abundance of Metarhizium anisopliae in Tasmanian pasture soils. Mycol. Res. 1992, 96, 378-384. [CrossRef]

23. Oddsdottir, E.S.; Nielsen, C.; Sen, R.; Harding, S.; Eilenberg, J.; Halldorsson, G. Distribution patterns of soil entomopathogenic and birch symbiotic ectomycorrhizal fungi across native woodland and degraded habitats in Iceland. Icel. Agric. Sci. 2010, $23,37-49$.

24. Uzman, D.; Pliester, J.; Leyer, I.; Entling, M.H.; Reineke, A. Drivers of entomopathogenic fungi presence in organic and conventional vineyard soils. Appl. Soil Ecol. 2019, 133, 89-97. [CrossRef]

25. Hallouti, A.; Ait Hamza, M.; Zahidi, A.; Ait Hammou, R.; Bouharroud, R.; Ait Ben Aoumar, A.; Boubaker, H. Diversity of entomopathogenic fungi associated with Mediterranean fruit fly (Ceratitis capitata (Diptera: Tephritidae)) in Moroccan Argan forests and nearby area: Impact of soil factors on their distribution. BMC Ecol. 2020, 20, 64. [CrossRef]

26. Moloinyane, S.; Addison, P.; Achiano, K.A.; Nchu, F. Association between chemical properties of vineyard soils and occurrence of entomopathogenic fungi causing different levels of mortality in Planococcus ficus. BioControl 2020, 65, 197-209. [CrossRef]

27. Sharma, L.; Oliveira, I.; Torres, L.; Marques, G. Entomopathogenic fungi in Portuguese vineyards soils: Suggesting a ‘GalleriaTenebrio-bait method' as bait-insects Galleria and Tenebrio significantly underestimate the respective recoveries of Metarhizium (robertsii) and Beauveria (bassiana). MycoKeys 2018, 38, 1-23. [CrossRef]

28. Sharma, L.; Oliveira, I.; Raimundo, F.; Torres, L.; Marques, G. Soil chemical properties barely perturb the abundance of entomopathogenic Fusarium oxysporum: A case study using a generalized linear mixed model for microbial pathogen occurrence count data. Pathogens 2018, 7, 89. [CrossRef]

29. Carlos, C.G.F.; Sousa, S.; Salvação, J.; Sharma, L.; Soares, R.; Manso, J.; Nóbrega, M.; Lopes, A.; Soares, S.; Aranha, J.; et al. Environmentally safe strategies to control the European grapevine moth, Lobesia botrana (Den. \& Schiff.) in the Douro demarcated region. Cienc. Tec. Vitivinic 2013, 28, 1006-1011.

30. Sharma, L.; Marques, G. Fusarium, an entomopathogen-a myth or reality? Pathogens 2018, 7, 93. [CrossRef]

31. Zazzerini, A.; Quaglia, M.; Davolio Marani, O. First report of Clonostachys rhizophaga as a pathogen of Dendrocalamus giganteus in Mozambique. Plant Dis. 2010, 94, 372. [CrossRef]

32. Imoulan, A.; Alaoui, A.; El Meziane, A. Natural occurrence of soil-borne entomopathogenic fungi in the Moroccan endemic forest of Argania spinosa and their pathogenicity to Ceratitis capitata. World J. Microbiol. Biotechnol. 2011, 27, 2619-2628. [CrossRef]

33. Keyser, C.A.; De Fine Licht, H.H.; Steinwender, B.M.; Meyling, N.V. Diversity within the entomopathogenic fungal species Metarhizium flavoviride associated with agricultural crops in Denmark. BMC Microbiol. 2015, 15, 249. [CrossRef] [PubMed]

34. Meyling, N.V.; Eilenberg, J. Occurrence and distribution of soil borne entomopathogenic fungi within a single organic agroecosystem. Agric. Ecosyst. Environ. 2006, 113, 336-341. [CrossRef]

35. Goble, T.A.; Dames, J.F.; Hill, M.P.; Moore, S.D. The effects of farming system, habitat type and bait type on the isolation of entomopathogenic fungi from citrus soils in the Eastern Cape Province, South Africa. BioControl 2010, 55, 399-412. [CrossRef]

36. Posadas, J.B.; Comerio, R.M.; Mini, J.I.; Nussenbaum, A.L.; Lecuona, R.E. A novel dodine-free selective medium based on the use of cetyl trimethyl ammonium bromide (CTAB) to isolate Beauveria bassiana, Metarhizium anisopliae sensu lato and Paecilomyces lilacinus from soil. Mycologia 2012, 104, 974-980. [CrossRef] [PubMed]

37. Ali-Shtayeh, M.S.; Mara'i, A.-B.B.M.; Jamous, R.M. Distribution, occurrence and characterization of entomopathogenic fungi in agricultural soil in the Palestinian area. Mycopathologia 2003, 156, 235-244. [CrossRef]

38. Sun, B.-D.; Liu, X.-Z. Occurrence and diversity of insect-associated fungi in natural soils in China. Appl. Soil Ecol. 2008, 39, 100-108. [CrossRef] 
39. Steinwender, B.M.; Enkerli, J.; Widmer, F.; Eilenberg, J.; Thorup-Kristensen, K.; Meyling, N.V. Molecular diversity of the entomopathogenic fungal Metarhizium community within an agroecosystem. J. Invertebr. Pathol. 2014, 123, 6-12. [CrossRef]

40. Möller, E.M.; Bahnweg, G.; Sandermann, H.; Geiger, H.H. A simple and efficient protocol for isolation of high molecular weight DNA from filamentous fungi, fruit bodies, and infected plant tissues. Nucleic Acids Res. 1992, 20, 6115-6116. [CrossRef]

41. Sharma, L.; Gonçalves, F.; Oliveira, I.; Torres, L.; Marques, G. Insect-associated fungi from naturally mycosed vine mealybug Planococcus ficus (Signoret) (Hemiptera: Pseudococcidae). Biocontrol. Sci. Technol. 2018, 28, 122-141. [CrossRef]

42. Yurkov, A.; Guerreiro, M.A.; Sharma, L.; Carvalho, C.; Fonseca, Á. Correction: Multigene Assessment of the Species Boundaries and Sexual Status of the Basidiomycetous Yeasts Cryptococcus flavescens and C. terrestris (Tremellales). PLoS ONE 2015, 10, e0126996. [CrossRef] [PubMed]

43. Bremner, J.M. Nitrogen-total. In Methods of Soil Analysis Part 3-Chemical Methods; Sparks, D.L., Page, A.L., Helmke, P.A., Loeppert, R.H., Eds.; Soil Science Society of America, American Society of Agronomy: Madison, WI, USA, 1996; pp. $1085-1121$.

44. Bower, C.A.; Reitemeier, R.F.; Fireman, M. Exchangeable cation analysis of saline and alkali soils. Soil Sci. 1952, 73, 251-262. [CrossRef]

45. Thomas, G.W. Soil pH and soil acidity. In Methods of Soil Analysis Part 3-Chemical Methods; Sparks, D.L., Page, A.L., Helmke, P.A., Loeppert, R.H., Eds.; Soil Science Society of America, American Society of Agronomy: Madison, WI, USA, 1996 ; pp. 475-490.

46. Faul, F.; Erdfelder, E.; Buchner, A.; Lang, A.-G. Statistical power analyses using G*Power 3.1: Tests for correlation and regression analyses. Behav. Res. Methods 2009, 41, 1149-1160. [CrossRef] [PubMed]

47. Jaronski, S.T. Ecological factors in the inundative use of fungal entomopathogens. BioControl 2010, 55, 159-185. [CrossRef]

48. Reeleder, R.D.; Miller, J.J.; Ball Coelho, B.R.; Roy, R.C. Impacts of tillage, cover crop, and nitrogen on populations of earthworms, microarthropods, and soil fungi in a cultivated fragile soil. Appl. Soil Ecol. 2006, 33, 243-257. [CrossRef]

49. Rousk, J.; Bååth, E. Fungal and bacterial growth in soil with plant materials of different C/N ratios. FEMS Microbiol. Ecol. 2007, 62, 258-267. [CrossRef]

50. Birkhofer, K.; Bezemer, T.M.; Bloem, J.; Bonkowski, M.; Christensen, S.; Dubois, D.; Ekelund, F.; Fließbach, A.; Gunst, L.; Hedlund, K.; et al. Long-term organic farming fosters below and aboveground biota: Implications for soil quality, biological control and productivity. Soil Biol. Biochem. 2008, 40, 2297-2308. [CrossRef]

51. Koorem, K.; Gazol, A.; Öpik, M.; Moora, M.; Saks, Ü.; Uibopuu, A.; Sõber, V.; Zobel, M. Soil nutrient content influences the abundance of soil microbes but not plant biomass at the small-scale. PLoS ONE 2014, 9, e91998. [CrossRef]

52. Bednarek, A.; Gaugler, R. Compatibility of soil amendments with entomopathogenic nematodes. J. Nematol. 1997, $29,220-227$.

53. Rangel, D.E.; Alston, D.G.; Roberts, D.W. Effects of physical and nutritional stress conditions during mycelial growth on conidial germination speed, adhesion to host cuticle, and virulence of Metarhizium anisopliae, an entomopathogenic fungus. Mycol. Res. 2008, 112, 1355-1361. [CrossRef]

54. Barelli, L.; Moonjely, S.; Behie, S.W.; Bidochka, M.J. Fungi with multifunctional lifestyles: Endophytic insect pathogenic fungi. Plant Mol. Bio. 2016, 90, 657-664. [CrossRef] [PubMed]

55. Morjan, W.E.; Pedigo, L.P.; Lewis, L.C. Fungicidal effects of glyphosate and glyphosate formulations on four species of entomopathogenic fungi. Environ. Entomol. 2002, 31, 1206-1212. [CrossRef]

56. Andaló, V.; Jr, A.; Santa-Cecília, L.; Souza, G. Compatibility of Beauveria bassiana with chemical pesticides for the control of the coffee root mealybug Dysmicoccus texensis Tinsley (Hemiptera: Pseudococcidae). Neotrop. Entomol. 2004, 33, 463-467. [CrossRef]

57. Meyling, N.V.; Eilenberg, J. Ecology of the entomopathogenic fungi Beauveria bassiana and Metarhizium anisopliae in temperate agroecosystems: Potential for conservation biological control. Biol. Control 2007, 43, 145-155. [CrossRef]

58. Klingen, I.; Haukeland, S. The soil as a reservoir for natural enemies of pest insects and mites with emphasis on fungi and nematodes. In An Ecological and Societal Approach to Biological Control; Eilenberg, J., Hokkanen, H.M.T., Eds.; Springer: Dordrecht, The Netherlands, 2006; pp. 145-211. [CrossRef]

59. Bidochka, M.J.; Kasperski, J.E.; Wild, G.A.M. Occurrence of the entomopathogenic fungi metarhizium anisopliae and Beauveria bassiana in soils from temperate and near-northern habitats. Can. J. Bot. 1998, 76, 1198-1204.

60. Cohen, E.; Joseph, T. Photostabilization of Beauveria bassiana conidia using anionic dyes. Appl. Clay Sci. 2009, 42, 569-574. [CrossRef]

61. Cozzi, G.; Somma, S.; Haidukowski, M.; Logrieco, A.F. Ochratoxin A management in vineyards by Lobesia botrana biocontrol. Toxins 2013, 5, 49-59. [CrossRef]

62. Sharma, L.; Bohra, N.; Singh, R.K.; Marques, G. Potential of Entomopathogenic Bacteria and Fungi. In Microbes for Sustainable Insect Pest Management: An Eco-Friendly Approach; Khan, M.A., Ahmad, W., Eds.; Springer International Publishing: Cham, Switzerland, 2019; Volume 1, pp. 115-149. [CrossRef]

63. Ownley, B.H.; Gwinn, K.D.; Vega, F.E. Endophytic fungal entomopathogens with activity against plant pathogens: Ecology and evolution. BioControl 2010, 55, 113-128. [CrossRef]

64. Lacey, L.A.; Grzywacz, D.; Shapiro-Ilan, D.I.; Frutos, R.; Brownbridge, M.; Goettel, M.S. Insect pathogens as biological control agents: Back to the future. J. Invertebr. Pathol. 2015, 132, 1-41. [CrossRef]

65. Scheepmaker, J.W.A.; Butt, T.M. Natural and released inoculum levels of entomopathogenic fungal biocontrol agents in soil in relation to risk assessment and in accordance with EU regulations. Biocontrol Sci. Technol. 2010, 20, 503-552. [CrossRef] 